\title{
Notas Farmacológicas \\ Antagonistas de los receptores de Leucotrienos: Rol en el manejo del Asma
}

\begin{abstract}
Grupo Farmacológico
Los antagonistas de los receptores de leucotrienos inhiben el efecto de los cisteinil-leucotrienos, los cuales representan a tres de los grandes mediadores del asma. Los leucotrienos son liberados por varios tipos de células y pueden causar inflamación ${ }^{1-2}$ y broncoconstricción. Los cisteinil-leucotrienos son mediadores particularmente importantes en pacientes con asma desencadenada por aspirina (AAS) ${ }^{3}$. Estos fármacos bloquean los receptores de los leucotrienos a nivel del músculo liso bronquial ${ }^{1-2}$, en forma selectiva, dosis dependiente y reversible. ${ }^{4}$
\end{abstract}

\section{Indicaciones}

Tratamiento del asma crónica leve o moderada en adultos. Como terapia aditiva, en pacientes refractarios a dosis bajas o moderadas de corticoides inhalatorios que aun están sintomáticos. Pacientes con asma severa que requieren altas dosis de corticoides inhalatorios y/u orales. Asma inducida por ejercicio y por AAS.

\section{Dosificación y grupos especiales}

Zafilukast: $20 \mathrm{mg} 2$ veces por día en ayunas (> 11 años). Niños de 7 a 11 años: $10 \mathrm{mg}$ cada 12 hs.

Montelukast: $10 \mathrm{mg}$ (en > 14 años) y $5 \mathrm{mg}$ masticable (entre 6-14 años) antes de acostarse.

La biodisponibilidad de zafilukast se ve afectada cuando se administra con las comidas, en promedio $40 \%$ menos con comidas grasas, por lo cual se recomienda administrarla con el estómago vacío, es decir 1 hora antes 02 hs depués de la comida.

Si bien el área bajo la curva del zafilukast aumenta en pacientes con cirrosis hepática y en mayores de 65 años, no hay recomendación específica acerca de modificar la dosis en estos grupos ni en insuficientes renales. En mujeres embarazadas no hay estudios para conocer el pasaje placentario, pero estudios en aminales sugirien pasaje placentario. También hay evidencia de pasaje a la leche de madres lactantes. ${ }^{4}$

\section{Efectos Adversos}

En general son bien tolerados. La evidencia proviene de estudios clínicos controlados aleatorizados que duraron hasta 4 años. La incidencia de efectos adversos serios es $1 \%$ y no difiere a la del placebo. La causa más común de discontinuación de la droga es exacerbación del asma (1,6\% en grupo zafirlukast y $2,6 \%$ en grupo placebo); cefalea $(12,9 \%$ en adultos y niños mayores de 12 años y 4,5\% en niños de 5 a11 años); infecciones de vías aéreas superiores (faringitis, rinitis) en mayores de 55 años (3,5\%). Otros efectos adversos menos frecuentes: reacciones de hipersensibilidad (urticaria, angioedema y rash), agranulocitosis, sangrado, edema, astenia, mialgias, fiebre, dolor generalizado o lumbar. Efectos adversos gastrointestinales: náuseas $(3,1 \%)$, diarrea (2,8\%); dolor abdominal (1,8\%); vómitos (1,5\%); dispepsia/ gastritis $(1,3 \%)$; elevación de TGP $(1,5 \%)$. La última no fue diferente del placebo y sólo en muy raros casos hubo insuficiencia hepática secundaria. ${ }^{4}$ Se repotaron raros casos de Sindrome de Churg-Strauss (vasculitis eosinofílica sistémica caracterizada por eosinofilia, rash cutáneo, peoría de síntomas pulmonares de tipo asmatiforme, complicaciones cardíacas y/o neuropatía), algunos de los cuales han sido asociados a disminución de los corticoides orales sistémicos. ${ }^{5}$

\section{Interacciones}

El Zafilukast inhibe el citocromo P450 y aumenta los efectos de la warfarina e interactúa con otras drogas como antihistamínicos y eritromicina (disminuyen la concentración de zafilukast), carbamazepina, fenitoína. No hay estudios con astemizol, cisapride, ciclosporina y dihidropiridinas pero se debe tener precaución por la vía de metabolismo. La asociación con teofilina y aspirina puede aumentar los niveles séricos de zafilukast. No interactúa con anticonceptivos orales.

\section{Monitoreo}

Si el paciente que está recibiendo estas drogas presenta algún signo de disfunción hepática (dolor en hipocondrio derecho, mal estado general, fiebre, ictericia, etc), se deberá dosar transaminasas. La suspensión se indica según el cuadro individual pesando riesgos y beneficios de la terapia. Si hay que indicar terapia concomitante con warfarina es necesario monitorear periódicamente el tiempo de protrombina.

\section{Efectividad}

El Zafilukast administrado cada 12 horas ha sido comparado con placebo en dos estudios ${ }^{6-7}$ aleatorizados publicados en pacientes mayores de 11 años (Tabla). Todavía no hay estudios que comparen Zafilukast con corticoides inhalatorios.

El Montelukast fue comparado con placebo en 11 estudios aleatorizados controlados. La mayoría de los estudios fueron diseñados para determinar la dosis y frecuencia de dosis, y mostraron que $10 \mathrm{mg}$ de Montelukast una vez por día al acostarse produce los efectos máximos en adultos. A las dosis recomendadas esta droga fue comparada con placebo en un estudio grande en adultos ${ }^{8}$ y otro en niños. ${ }^{9}$ En un estudio de 110 pacientès con asma inducida por ejercicio, la reducción máxima del VEF1 asociado con ejercicio fue $32,4 \%$ con placebo comparado a $22,2 \%$ con montelukast. $10 \mathrm{Un}$ estudio que compara montelukast con corticoides inhalatorios y placebo en adultos con asma crónica, el montelukast fue mejor pero no tan efectivo como bajas dosis de beclometasona inhalatoria ${ }^{11}$ (Tabla).

El efecto global en los estudios, aunque estadísticamente significativos, es pequeño y de significancia clínica cuestionable. El efecto de la tasa de pico flujo en el hogar, aumento 20L/min. (6\%), y es máximo el día después de la primera dosis. ${ }^{4}$ Datos limitados sugieren que el efecto terapéutico del zafilukast (mejoría de los síntomas de asma y del VEF, con el consecuente menor requerimiento de agonistas beta 2) se observa en general dentro de la primer semana de tratamiento.

Tabla: Ensayos aleatorizados de inhibidores de leucotrienos

\begin{tabular}{|c|c|c|c|c|}
\hline \multirow[t]{2}{*}{ Droga y dosis } & \multirow[t]{2}{*}{$\mathrm{N}$} & \multicolumn{2}{|c|}{ Resultados } & \multirow[t]{2}{*}{ Detalles del estudio } \\
\hline & & AVEF $1 \#$ & \begin{tabular}{|l|} 
B2 \\
agosnista*
\end{tabular} & \\
\hline $\begin{array}{l}\text { Zafilukast } 6 \\
\text { (20mg 2/d) } \\
\text { Placebo }\end{array}$ & $\begin{array}{l}57 \\
56 \\
\end{array}$ & $\begin{array}{l}+11 \% \\
+1 \% \\
\end{array}$ & $\begin{array}{l}-31 \% \\
-15 \% \\
\end{array}$ & $\begin{array}{l}\text { Asma crónica } \\
\text { Edad: } 18-65 \\
6 \text { semanas } \\
\end{array}$ \\
\hline $\begin{array}{l}\text { Zafilukast } 7 \\
\text { (20mg 2/d) } \\
\text { Placebo }\end{array}$ & $\begin{array}{l}514 \\
248 \\
\end{array}$ & $\begin{array}{l}+5,6 \% \\
+1 \%\end{array}$ & $\begin{array}{l}-22,3 \% \\
+7 \%\end{array}$ & $\begin{array}{l}\text { Asma crónica } \\
\text { Edad: }>11 \\
13 \text { semanas }\end{array}$ \\
\hline $\begin{array}{l}\text { Montelukast }{ }^{8}(10 \mathrm{mg}) \\
\text { Placebo }\end{array}$ & $\begin{array}{l}408 \\
273\end{array}$ & $\begin{array}{l}+13 \% \\
+4,2 \%\end{array}$ & $\begin{array}{c}-25 \% \\
0 \%\end{array}$ & $\begin{array}{l}\text { Asma crónica } \\
\text { Edad: }>14 \\
12 \text { semanas } \\
\end{array}$ \\
\hline $\begin{array}{l}\text { Montelukast }{ }^{9}(5 \mathrm{mg}) \\
\text { Placebo }\end{array}$ & $\begin{array}{l}201 \\
135\end{array}$ & $\begin{array}{l}+8,2 \% \\
+3,6 \%\end{array}$ & $\begin{array}{l}-12 \% \\
+6 \%\end{array}$ & $\begin{array}{l}\text { Asma crónica } \\
\text { Edad: } 6-14 \\
8 \text { semanas } \\
\end{array}$ \\
\hline $\begin{array}{l}\text { Beclometasona11 } \\
(200 \mathrm{mg} 2 / \mathrm{d}) \\
\text { Montelukast (10mg) } \\
\text { Placebo }\end{array}$ & $\begin{array}{l}251 \\
387 \\
257 \\
\end{array}$ & $\begin{array}{l}+13,1 \% \\
+7,4 \% \\
+0,7 \% \\
\end{array}$ & $\begin{array}{l}-40 \% \\
-24 \% \\
0 \% \\
\end{array}$ & $\begin{array}{l}\text { Asma crónica } \\
\text { Edad: } 15-85 \\
12 \text { semanas }\end{array}$ \\
\hline $\begin{array}{l}\text { Montelukast } 12 \\
\text { Salmeterol }\end{array}$ & $\begin{array}{l}97 \\
94\end{array}$ & $\begin{array}{l}57.2 \% \$ \\
33.0 \%\end{array}$ & $\overline{-}$ & $\begin{array}{l}\text { Asma de ejercicio } \\
\text { Adultos } \\
8 \text { semanas } \\
\end{array}$ \\
\hline $\begin{array}{l}\text { Montelukast }{ }^{10} \\
\text { Placebo }\end{array}$ & $\begin{array}{l}54 \\
56\end{array}$ & $\begin{array}{l}47 \% \text { de } \\
\text { reducción de } \\
\text { broncocons- } \\
\text { tricción indu- } \\
\text { cida por ejer- } \\
\text { cicio }\end{array}$ & $\begin{array}{l}14 \% @ \\
36 \%\end{array}$ & $\begin{array}{l}\text { Asma leve de ejercicio } \\
\text { Edad: } 15-45 \\
12 \text { semanas }\end{array}$ \\
\hline
\end{tabular}

B2 aqonistas: Inhaladores (Ej. Salbutamol), \$ \% de inhibición de la disminución del VEF1, utilización de B2 de rescate 
Nombres comerciales, presentaciones y precios \&

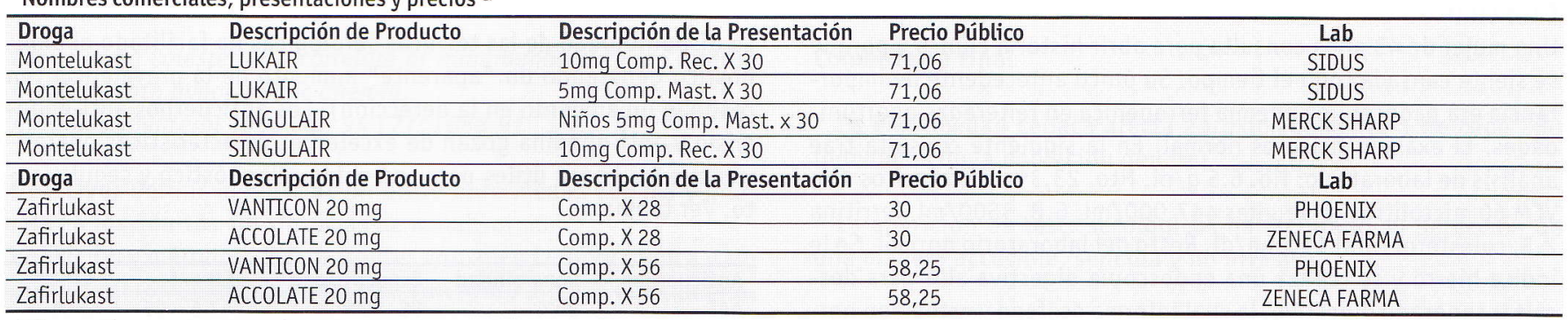

\&(Argentina, Agosto 2000)

Es decir que el costo mensual del tratamiento es de $\$ 60$ a 70 , considerando las distintas dosis.

\section{Comentarios}

La eficacia de estas drogas ha sido valorada en general a través de estudios clínicos controlados y aleatorizados efectuados a un corto plazo, menos de 12 semanas, comparados con placebo, no con tratamiento habitual o recomendado hasta el momento, y con puntos finales intermedios como mejoría del volumen espirado en el primer segundo o disminución del requerimiento de agonistas beta ${ }^{2}$.

Cuando uno se enfrenta a la decisión de una nueva droga en el consultorio, la primera pregunta que se hace es ¿qué droga es mejor para este paciente con asma? Y "mejor" implica mayor eficacia con costo igual o menor, en una droga bien tolerada. La eficacia puede ser primaria (puntos finales intermedios como mejoría en funcional respiratorio) o secundaria, en general valorada luego de muchos años de una droga en el mercado (disminución de puntos finales más duros como internaciones, mortalidad etc).

La comparación contra placebo y no contra corticoides inhalatorios es un problema no menor y muy habitual cuando se trata de aprobación de una droga por la FDA. Cuendo se comparó con corticoides inhalados, la eficacia de los inhibidores de leucotrienos fue menos. De allí surge la consideración de la posibilidad de jugar un papel como terapia aditiva, cuando no hay mejoría significativa o suficiente con el tratamiento actual. Todavía no hay datos para responder esta cuestión con precisión. Otros puntos finales aún poco válorados son la calidad de vida del paciente asmático, la autopercepción de la mejoría sinto- mática, la prevención de exacerbaciones, la incidencia de infecciones de las vías aéreas y la mortalidad. Por otro lado, conocemos menos datos de seguridad a largo plazo que el mejor tratamiento disponible. (máximo tiempo de estudio 4 años).

Por todas estas razones las indicaciones a resaltar, según nuestra perspectiva, serían:

1) Tratamiento del asma crónica leve o moderada en adultos que no pueden o no quieren usar corticoides inhalados.

2) Terapia aditiva en pacientes refractarios a cualquier dosis de corticoides inhalatorios que persisten sintomáticos, (probar previamente altas dosis o uso de aerocámara)

3) Pacientes con asma severa que requieren altas dosis de corticoides inhalatorios y/u orales, y cuyo efecto del tratamiento es insuficiente. 4) Asma inducido por ejercicio y por AAS 12

La ventaja más tentadora de este grupo de drogas es su administración por vía oral con el consecuente menor esfuerzo educativo. Debemos tener en cuenta, sin embargo, que la evidencia disponible a la actualidad no avala el reemplazo de los corticoides inhalados.

Esta Nota está adaptada en parte de Therapeutics Letter, issue 29, Abril/ Mayo 1999

Dra. Gabriela Lewin y Dra. Marcela Botargues

Unidad de Medicina Familiar y Preventiva. Hospital Italiano de Buenos Aires.

\section{Referencias}

1. Sampson A, Holgate S. Leukotriene modifiers in the treatment of asthma. Brit Med J 1998;316:1257-1258.

2. Renzi P. Antileukotriene agents in asthma: The dart that kills the elefant? CMAJ 1999;160:217-23.

3. Christie PE. Aspirin sensitive asthma. Curr Med Lit Respir Med 1997;11:63-73.

4. AHFS (American Hospital Formulary Society). Drug information 2000.

5. Wechsler ME, Garpestad E, Flier SR, et al. Pulmonary inflitrates, eosinophilia, and cardiomyopathy following corticosteriod withdrawal with asthma receiving zafilukast. J Amer med Assoc 1998;279:455-457.

6. Fish LE, Kemp JP, Lockey RF, et al. Zafilukast for symptomatic mild-to-moderate asthma: A 13-week multicenter study. Clin Therap 1997;19:675-690.

7. Spector SL, Smith LJ, Glass M. Effects of 6 weeks of therapy with oral doses of ICI 204, 219, a leukotriene D4 receptor antagonist, in subjects with bronchial asthma. Amer J Respir Crit care Med 1994;150:618-23.

8. Reiss TF, Chervinsky P, Dockhorn RJ, et al. Montelukast, a once-daily leukotriene receptor antagonist, in the treatment of chronic asthma. Arch Intern Med 1998;158:1213-20.

9. Knorr B et al. Montelukast for chronic asthma in 6 to 14 year-old children. JAMA 1998; 279:1181-6.

10. Leff JA, Busse WW, Pearlman D, et al. Montelukast, a leukotriene-receptor antagonist, for the treatment of mild asthma and exercise-induced bronchoconstriction. N Engl J Med 1998;339:147-52

11. Malmstrom K, rodriguez-Gomez G, Guerra J, et al. Oral montelukast, inhaled beclometasone, and placebo for chronic asthma: a randomized controlled trial. Ann Intern Med 1999;130:487-495.

12. Oral Montelukast compared with inhaled salmeterol to prevent exercise-induced bronchoconstriction. Annals of Internal Medicine 2000 enero 18 ; $132(2): 97-104$. 